$10-1-2021$

\title{
A Need of Further Training for Marriage and Family Therapy Students' on Food Addiction and Related Eating Disorders
}

\author{
Darren D. Moore \\ Touro University Worldwide, mooredd2012@gmail.com \\ Chichun Lin \\ John Hopkins University, linqijun2010@gmail.com \\ Clinton Cooper \\ 0clintc7@gmail.com
}

Follow this and additional works at: https://nsuworks.nova.edu/tqr

Digitadrt of the Counseling Psychology Commons, Counselor Education Commons, Health Psychology Commens, and the Other Psychology Commons

Network

ТФ98 Article has supplementary content. View the full record on NSUWorks here:

https://nsuworks.nova.edu/tqr/vol26/iss10/4

\section{Recommended APA Citation}

Moore, D. D., Lin, C., \& Cooper, C. (2021). A Need of Further Training for Marriage and Family Therapy Students' on Food Addiction and Related Eating Disorders. The Qualitative Report, 26(10), 3046-3066. https://doi.org/10.46743/2160-3715/2021.4533 


\title{
A Need of Further Training for Marriage and Family Therapy Students' on Food Addiction and Related Eating Disorders
}

\author{
Abstract \\ The purpose of this study was to explore Marriage and Family Therapy students' perspectives regarding \\ food addiction and associated eating disorders, as a clinical treatment issue. In a standard addictions \\ course housed in a Marriage and Family Therapy program approved by the Commission on Accreditation \\ for Marriage and Family Therapy Education (COAMFTE), 20 students completed a qualitative survey \\ where they reflected on the topic of food addiction, Binge Eating Disorder, and Bulimia Nervosa, within the \\ context of individual, couple, and family relationships. In the study four major themes emerged, which \\ included (1) Defining Food Addiction, (2) Perceptions of Eating Disorders, (3) Conceptualizing Systemic \\ Treatment, and (4) Experiences in clinical training. Clinical implications, recommendations for MFT \\ education, clinical practice, and future research are discussed. Findings suggest that while MFT students \\ in the study were well versed in conceptualized systemic treatment, it was of a general treatment and \\ understanding using MFT theory, and not in relation to or specifically concerning food addictions and their \\ connection or distinction from Binge Eating Disorder and/or other eating disorders found in the \\ Diagnostic and Statistical Manual, potentially impacting the level of skillfully and appropriately working \\ with clients.

\section{Keywords} \\ food addiction, eating disorders, marriage and family therapy, qualitative research

\section{Creative Commons License} \\ Creative \\ Commons \\ This work is licensed under a Creative Commons Attribution-Noncommercial-Share Alike 4.0 International \\ Attribution \\ Honcensemmercial \\ 4.0 \\ License
}




\title{
A Need of Further Training for Marriage and Family Therapy Students on Food Addiction and Related Eating Disorders
}

\author{
Darren D. Moore \\ Touro University Worldwide, Los Alamitos, California, USA \\ Chichun Lin \\ John Hopkins University, Baltimore, Maryland, USA \\ Clinton E. Cooper \\ Independent Author, Scottsdale, Arizona
}

\begin{abstract}
The purpose of this study was to explore Marriage and Family Therapy students' perspectives regarding food addiction and associated eating disorders, as a clinical treatment issue. In a standard addictions course housed in a Marriage and Family Therapy program approved by the Commission on Accreditation for Marriage and Family Therapy Education (COAMFTE), 20 students completed a qualitative survey where they reflected on the topic of food addiction, Binge Eating Disorder, and Bulimia Nervosa, within the context of individual, couple, and family relationships. In the study four major themes emerged, which included (1) Defining Food Addiction, (2) Perceptions of Eating Disorders, (3) Conceptualizing Systemic Treatment, and (4) Experiences in clinical training. Clinical implications, recommendations for MFT education, clinical practice, and future research are discussed. Findings suggest that while MFT students in the study were well versed in conceptualized systemic treatment, it was of a general treatment and understanding using MFT theory, and not in relation to or specifically concerning food addictions and their connection or distinction from Binge Eating Disorder and/or other eating disorders found in the Diagnostic and Statistical Manual, potentially impacting the level of skillfully and appropriately working with clients.
\end{abstract}

Keywords: food addiction, eating disorders, marriage and family therapy, qualitative research

\section{Introduction}

What is food addiction and how do marriage and family therapists conceptualize it within the context of clinical practice? Is food addiction real or simply a concept that is underdeveloped, yet sensationalized in the media and scholarly literature? Further, what are the clinical implications of this ambiguity in the field of mental health and the general population? The topic of food addiction has been the subject of debate for quite some time with new researchers suggesting that food addiction can be viewed in a similar, but different way than traditional addictions (i.e., substance abuse) and eating disorders (i.e., Binge Eating Disorder and Bulimia; Ziauddeen \& Fletcher, 2013). Some researchers have suggested that a portion of the population indeed experience the addictive-like responses to high-sugar, high-fat, and highly processed foods (Avena, Bocarsly et al., 2008). 
Further, some researchers have suggested that addictive-like responses are associated with the brain's neurochemical changes and reward systems, which suggest that some food alone can be addictive (like substances such as alcohol, tobacco, heroin, cocaine, or marijuana; Schulte et al., 2015; Schulte et al., 2016; Ziauddeen \& Fletcher, 2013). Other researchers have argued that individuals with food addiction may not be addicted to all foods, rather they may be addicted to some foods that negatively impact one's overall health and well-being (Avena, Rada et al., 2008; Davis \& Carter, 2009; Davis et al., 2011; Goldstein \& Volkow, 2011; Pelchat, 2009; Volkow et al., 2011). Therefore, some researchers have supported the notion that food addiction should be viewed as more of a substance use disorder as opposed to as an eating disorder. (Goldstein \& Volkow, 2011; Imperatori et al., 2014; Nutt et al., 2010; Pelchat et al., 2004; Ziauddeen \& Fletcher, 2013).

However, there is major uncertainty among other scholars who have suggested that food addiction is just a part of a behavioral issue and is more related to food compulsion and eating disorders (Ziauddeen \& Fletcher, 2013). With bulimia being viewed as an issue where individuals engage in binge eating, experience loss of control related to food consumption, and experience negative compensatory behaviors (Fairburn et al., 2000); food addiction has been viewed as an eating disorder that is more psychological and behavioral in nature as opposed to rooted in a "true addiction" (Hebebrand et al., 2014). Likewise, with the emergence of Binge Eating Disorder in the DSM-V, some individuals have chosen to view food addiction as a behavioral issue and mental illness (Fairburn et al., 1998). Some researchers have suggested that food addiction should be categorized as Binge Eating Disorder or "Eating Addiction" and thus treated as a psychological issue related to compulsion instead of an issue that is induced by a chemical reaction in the brain (Hone-Blanchet \& Fecteau, 2014). Others suggest that there are underlying similarities between eating disorders and food addiction, which may present itself at various times during a person's lifespan (Gearhardt, White et al., 2011). Others suggest that food addiction, eating disorders (Pursey et al., 2016), food addiction, and obesity (Schulte et al., 2016) are correlated. Further, some have argued against the notion of food addiction and its use in the DSM and in clinical work, with some reporting that food addiction trivializes "real addiction" (Rogers, 2017). In addition, others believe that food addiction as a phenomenon, simply has not been substantiated (Pressman et al., 2015).

While "food addiction" is still highly debated across disciplines, many agree that issues around excessive eating, loss of control, and in some cases compensatory behaviors is an issue that can impact individuals, couples, and families. For example, Ziauddeen and Fletcher (2013) suggested that it is necessary to get diverse views from researchers and professionals in different areas to construct a holistic concept of food addiction for academic and clinical applications. In the field of marriage and family therapy, there has been a significant amount of discussion regarding eating disorders and their treatment (Eisler et al., 1997; Geist et al., 2000; Lock, \& le Grange, 2005). However, there has been less of a discussion specifically regarding the notion of food addiction and potentially related disorders that may present itself in therapy to include Binge Eating Disorder and Bulimia. With the increasing numbers of marriage and family therapists (MFTs) working with clients who present with food-related, eating-related, and weight-related issues (Geist et al., 2000; Lemmon \& Josephson, 2001; Moore \& Cooper, 2016), a deeper exploration of MFTs' perspectives and training of food addiction and eating disorders and their clinical treatment of these issues should be explored.

Further, gaining some insight regarding how MFT students conceptualize food addictions and eating disorders may contribute to furthering how practitioners go about creating change within and outside of the therapy room. Thus, the purpose of this study was to explore how perspective MFTs conceptualize food addiction and eating disorders, within the context of clinical treatment as it pertains to shaping how these issues are treated in the field of marriage and family therapy and the greater field of mental health. In addition, the purpose was 
to gain additional insight regarding the epistemology of MFT students specifically related to food addiction, including how they know what they know, and to explore how their knowledge impacts how they think about treatment and potential clinical intervention. This is specifically important to researchers, as it highlights how future clinicians view and understand the educational and clinical training and application of food addiction and eating disorders as individuals entering the field. The overall research questions were, "What is food addiction and how do you think about it as a marriage and family therapist?" Additional overarching questions included "How do you think about binge eating disorder and bulimia, within the context of food addictions?" and "How do you conceptualize treatment?"

\section{Literature Review}

\section{Lack of MFTs' Perspectives on Food Addiction}

To inform the current study, authors began their inquiry for information by researching food addiction in the field of Marriage and Family Therapy (MFT). Although there exist many articles exploring the applications of MFT approaches on eating disorders, there are not as many articles discussing the use of MFT theories and techniques specifically related to food addictions. Further, there is a dearth of literature that specifically addresses how MFT's come to know how to work with clients who may present with issues related to food addiction.

\section{Eating Disorder and Relevant Development in Marriage and Family Therapy (MFT)}

As a result, researchers turned their focus to eating disorders and relevant developments in Marriage and Family Therapy, where it was found that binge eating disorder was considered a major impact on food addiction (Meule \& Gearhardt, 2014). In DSM-V, binge eating episodes are associated with (1) eating much more rapidly than normal; (2) eating until feeling uncomfortably full; (3) eating a lot when not feeling hungry; (4) eating alone because of feeling embarrassed by other's perceptions; (5) feeling disgusted, depressed, or guilt after eating so much (American Psychiatric Association, 2013).

Currently, there are seven major approaches that MFTs apply for eating disorders in the context of child, couple, and family therapy. The most common one is psychoeducation where MFTs help clients understand the definitions, development, and impacts of eating disorders and teach clients how to supportively behave toward the child, partner, or family member with the diagnosed eating disorder (Gerstein \& Pollack, 2016; Siegel et al., 2009). The second one is the Maudsley approach in which the parent plays an active and positive role and takes full control over the child's food intake to helping restore the child's weight a normal level of body mass index (BMI), which is in-between 18.5 and 24.9 (Fairburn, 2005; Treasure et al., 2007). Many foundational MFT approaches are also applied to the treatment of clients with eating disorder. Structural family therapists attempt to challenge the old family structure that accommodates the eating disorder and to create a strong parental hierarchy for enforcing the boundaries between the child and the behaviors of eating disorders (Gerstein \& Pollack, 2016; Minuchin \& Fishman 2009; Nichols \& Schwartz, 2005). Bowenian family therapists are concerned about the potential dangers of passing down the behaviors of eating disorders from one generation to the next generation and worry about the projections of fear of parents who failed to deal with their behaviors of eating disorders on their children. Thus, MFTs work on the parents' behaviors and emotion to avoid the dysfunctional intergenerational transmission (Bowen, 1978; Gerstein \& Pollack, 2016). Experiential MFTs focus on feeling and communication about the impacts of eating disorders on couple or family relationships (Nichols \& Schwartz, 2005). The sixth recommended approach is Emotion-focused Family 
Therapy which helps family members interact in a healthier way dealing with issues of eating disorders and enhance the role and support of partners or parents of the client with the eating disorder, including mastering the skills and feelings involved in recovery coaching, mastering emotion coaching, and managing emotional blocks (Lafrance et al, 2016). The last approach is the Uniting Couples Anorexia Nervosa program which is a couple-based intervention addressing psychoeducation, communication, empathy, healthy interaction, body image, and relapse prevention on the partner's eating disorder (Kirby et al., 2016).

\section{Development of Food Addiction Measurement}

To provide a standardized assessment of food addiction, the Yale Food Addiction Scale (YFAS) was developed with 25-item instrument measures (Gearhardt et al., 2009). The development of YFAS was based on the DSM-IV substance dependence criteria, including (1) tolerance; (2) withdrawal symptoms; (3) substance taken in larger amount; (4) repeated unsuccessful attempt to quit; (5) increased effort to obtain, use, or recover from its effects; (6) reduction of social, occupational, or recreational activities; (7) use of the substance despite a persistent physical or psychological problem caused by the substance (American Psychiatric Association, 1994). According to the statistical findings based on YFAS, there were about 5$10 \%$ in non-clinical samples, $15-25 \%$ in obese samples, and $30-50 \%$ in morbidly obese bariatric patients or obese individuals with binge eating disorder (Meule \& Gearhardt, 2014).

\section{Increased Research Interests on Food Addiction}

The term "food addiction" was initially introduced by Theron Randolph (1956). From 1956 to 2000, there were many articles about comparisons between addiction and eating behaviors (De Silva \& Eysenck, 1987; Hetherington \& MacDiarmid, 1993; Rogers \& Smit, 2000; Szmukler \& Tantam, 1984). Since 2009, the number of publications focused on the term "food addiction" was greatly increased (Gearhardt, Davis et al., 2011). The increased publications were driven by the rise of findings that binge eating was associated with alterations in dopaminergic signaling and food-cue elicited hyperactivation of reward-related brain areas (Schienle et al., 2009).

This research study specifically seeks to address the nature of epistemology, education, and treatment of food addiction and the inclusion of perspective MFT's in their understanding and conceptualization of food addiction and other eating disorders. This research may inform the future of MFT education as well as may contribute to the discussion of food addiction within and outside of the scientific and practitioner-based community.

\section{Methodology}

For the study, the authors were interested in exploring how MFT students conceptualize food addiction and related eating disorders as a clinical issue. The focus was on gaining insight into how students define food addiction and related eating disorders as well as how they construct meaning around treatment. Further, the authors wanted to gain some understanding about the training and exposure that students receive in MFT training programs as this may help shape how these future therapists may conceptualize the treatment of food addiction and other food and eating related disorders. Authors were interested in the experiences and perspectives of students in consideration to the needs of students in an educational setting. Researchers were not interested in assessing correlation among variables or predicting outcomes; and therefore, did not use a quantitative method. Qualitative description was selected because researchers viewed this study as preliminary and were not attempting to build 
a theory; therefore, Grounded Theory was not selected. While researchers were interested in experiences, researchers viewed this study more preliminary study and thus focused on description (qualitative description) and not meaning making (phenomenology).

\section{Qualitative Inquiry}

For this study, the authors utilized qualitative inquiry in the form of a written survey as these allowed participants to elaborate in complete thoughts to each question. Qualitative inquiry generally is useful for research where there is a focus on gaining understanding about experiences and perspectives (Merriam, 2002) and was more favorable than quantitative approach given the scope of the study. While there are a variety of methodological approaches that can be utilized under the umbrella of qualitative inquiry such as phenomenology (Earle, 2010), grounded theory (Corbin \& Strauss, 1990), case study, (Flyvbjerg, 2006) and focus groups, among others (Kitzinger, 1995); qualitative description was selected as it was the most congruent with the research questions and method of data collection. Researchers were interested in the experiences and perspectives of participants as students and future therapists and their needs in an educational setting. Further, the authors viewed the current study as a preliminary study focused on qualitative description and not phenomenological meaningmaking or in grounded theory to develop any theory from this research.

\section{Qualitative Description}

Qualitative description is a method of inquiry that is focused on explicating and describing one's perspective or experience. The focus of qualitative description is less about interpretation and more about adequately describing the data when compared to other types of inquiry such as phenomenology and grounded theory (Sandelowski, 2000). In qualitative description, researchers stay close to the data by taking the results at face value with less potential for interpretive error (Sandelowski, 2000). When discussing qualitative description, Neergaard et al. (2009), assert the following:

Qualitative description differs from other qualitative methods in several ways. Firstly, in terms of analysis, the aim of Qualitative description is neither thick description (ethnography), theory development (grounded theory) nor interpretative meaning of an experience (phenomenology), but a rich, straight description of an experience or an event. This means that in the analytical process and presentation of data, researchers using qualitative description stay closer to the data. Whereas other qualitative approaches often aim to develop concepts and analyze data in a reflective or interpretive interplay with existing theories, the final product of qualitative description is a description of informants' experiences in a language. (p. 53)

Likewise, in qualitative description, researchers draw from naturalistic inquiry with less emphasis on a preconceived theoretical framework (Lambert \& Lambert, 2012). While there is some degree of interpretation involved in all qualitative research, in qualitative description, authors maintain proximity to the data. Therefore, the result of qualitative description is a rich description rooted in the language of the respondents, as opposed to exploring how one understands or constructs meaning as often the case in phenomenology (Merriam, 2002). Given that the focus of the study was about understanding how MFT students define food addiction, qualitative description was the most appropriate method of scientific inquiry. In this study, the researchers were less interested in theory development or understanding the meaning of a 
particular experience. Likewise, the researchers were more interested in gaining insight about how students define food addiction, with an emphasis on knowledge, perception, and direct clinical treatment.

\section{Recruitment}

This study originated as part of a course assignment in an MFT training program located in the southern part of the United States. In an MFT training program accredited by the Commission on Accreditation for Marriage and Family Therapy Education, students are required to take a course related to substance abuse prevention and intervention. This course was generally taken during student's final year in the training program. Prior to this course, students had taken standard courses in MFT curriculum offered by most COAMFTE programs, and students were involved in working with clients in various settings locally in the community. While the course was primarily focused on traditional substance abuse topics (i.e., drugs and alcohol), there was some discussion related to addiction as a general framework to include substance use and abuse, food addiction, gambling addiction, among other topics within a systems-based framework. As part of the course, students were engaged in various assignments that were geared towards exploring their epistemology related to addiction in general and food addiction. One assignment involved students being required to write a narrative related to addiction that explored how students currently understood addiction. Further, MFT students were asked to complete a qualitative survey where they answered questions related to their current attitudes and perspectives regarding food addiction, which included how students thought about clinical treatment. This research study is focused on the results of the qualitative survey. The respondents in the study included students that completed the assignment who also gave consent for their work to be used as research, as required, and approved by the school's institutional review board.

\section{Demographics}

Eighteen students completed the survey, of which there were two identified as male and 16 identified as female. The average age in the group of students was 28.5 years. In the study, eight students identified as "White," while slightly over half of the students reported that they identified as "African American." The survey asked a variety of questions, some of which included self-reported body mass index information (BMI). Based on the results, the average body mass index of students was 29 (overweight). Students were asked how they identified themselves in terms of being under-weight, "normal" weight, overweight, or obese. None of the students reported as obese (although 6 out of the 18 met or exceeded BMI criteria for the classification of obesity). Students were asked a series of questions related to addiction in general and then more specifically questions related to obesity, food consumption, and weight. Students were asked if they or if anyone in their family of origin had any history related to substance abuse. In the study, one student reported a personal history of substance abuse which was reported as "nicotine and caffeine." Nine students reported having members of their family of origin that have had issues with substance abuse, with the majority being alcoholism and various substance use and abuse. There were two students that reported that there was substantial alcoholism in their families of origin which resulted in involvement with the legal problems. Students were also asked if they had any family history or personal issues related to obesity and its co-morbidities, weight concerns, negative body image, or issues with food consumption. In the study, eight students reported in the affirmative about their own personal experiences. The issues that were reported included "negative body image or body dissatisfaction, being overweight, experiencing unwanted weight gain, experiencing periods of 
yo-yo dieting, experiencing periods of living a sedentary life, engaging in intense exercise to compensate for overeating, binging, excessive caloric restriction, fasting, starvation, fasting, and purging." In the study, nine students reported that there were concerns related to obesity and its co-morbidities, weight, body image, and food consumption in their families or origin, with some concerns including:

Diabetes, hypertension, hypercholesterolemia, heart disease, obstructive sleep apnea, coronary artery disease, knee, and joint issues due to excess weight, thyroid problems, struggles with being overweight and obese, negative body image, engagement in fad diets, binging, purging, and having a history of making unhealthy decisions related to diet and exercise.

\section{Data Collection}

The qualitative survey that was given consisted of a series of demographic questions, short answer questions, and experiential questions. In particular, the demographic section required students to select a pseudonym for purposes of confidentiality. Students were asked to self-report regarding various contextual factors including age, race, religion, height, weight, body mass index, relationship status, number of children, and personal and family history related to substance abuse, body size, and food consumption. The survey consisted of 24 short answer questions, with nine questions focused specifically on food addiction and eating disorders, and the remaining questions pertaining to an experiential assignment. The nine questions discussed in this study focused on student's epistemology regarding food addictions and related eating disorders, including topics as how one defines food addiction and eating disorders, how one conceptualizes clinical treatment, and exposure to working with the population prior to and during the MFT training program. For a list of sample questions please see Appendix A.

\section{Analysis}

The authors utilized a two-pronged method when approaching the analysis of the data. The authors initially reviewed the surveys independently several times. This included the authors first reviewing each survey individually and taking notes in the margins, related to general ideas, thoughts, reflections, and patterns that were noticed from the surveys. After reading all the surveys globally (becoming immersed in the data), the authors then initiated a review of the data specifically with the purpose of coding each survey individually. Coding each individual case, also referred to as decontextualization (Starks \& Trinidad, 2007) involved each author re-reading each individual survey, paying close attention to key words, phrases, definitions, experiences, and patterns in the data (Gläser \& Laudel, 2013). According to McCracken (1988), the object of data analysis is to identify categories and to establish the relationships and assumptions that inform how participants make sense of their experience. While the authors were guided by the original overarching research questions, the authors did not develop a preexisting coding scheme prior to reviewing the surveys. Therefore, the authors utilized an inductive approach when involved in the data analysis process and utilized open coding. Initially coding was conducted manually utilizing Microsoft word and later a computer software program (NVivo) was used to assist with coding data (Basit, 2003).

After decontextualization and assessing cases individually, the author, compared the codes developed across cases to refine the codes and engage in recontextualization (Tesch, 1990). According to Ayres et al. (2003), recontextualization is where data are "reintegrated into themes that combine units of like meaning taken from the accounts of multiple research 
respondents" (p. 872). During this time, the authors compared the results of the surveys along with the corresponding codes, to develop a preliminary list of key concepts or themes. Developing key themes involved observing the codes for all surveys, compiling them into categories, and then collapsing the categories based on the overarching themes (Elo \& Kyngäs, 2008). This included what some authors refer to as "reducing complexity" (Burnard, 1991) by grouping categories under higher ordered and broader headings. These themes were then brought to a meeting that took place between the authors. During this meeting, the authors provided a report on their version of original codes and preliminary themes. Additionally, during the meeting, the authors were able to gain insight into each other's perspectives, discuss areas where researchers were congruent in their research findings, and discuss any potential areas of opposition. During this meeting, researchers were able to work together collaboratively to develop the final list of themes. For a specific exemplar of the analytical process to reach a theme from the coding process, please see Appendix B.

\section{Credibility and Transferability}

The authors employed a variety of mechanisms to increase scientific rigor in the study. Reflexivity was incorporated by the authors prior to and during data collection. Reflexivity is a process by which authors engage in reflection regarding their epistemology and positionality as it relates to the research topic, (Berger, 2015; Gilgun, 2010; Palaganas et al., 2017). Prior to the study, the first author conducted a self-narrative where he evaluated his own perspective and potential biases regarding food addiction and eating disorders. Likewise, upon starting the project, the second and third authors reviewed their perspective and potential biases related to food addiction and eating disorders. In addition, the narratives were shared with one another and discussed (Moore et al., 2018).

The first author is an Associate Professor and Program Director in a Marriage and Family Therapy Program, who has extensive experience teaching, conducting research, and providing direct clinical services with clients who have struggled with eating disorders, among other issues. The first author has a doctoral degree in Marriage and Family Therapy from a university accredited by the Commission on Accreditation for Marriage and Family Therapy. The first author completed additional training in behavioral medicine and sleep, as well as Health Disparities Research in post-doctoral training programs. Further, the second author obtained a Master of Arts degree in Higher and Postsecondary Education (MAED) from Teachers College, Columbia University. As a Licensed Marriage and Family Therapist, the first author works to assist clients who struggle with general mental health issues as well as issues specific to Anorexia, Bulimia, Binge Eating Disorder, food compulsion, weight and weight loss, negative body image, and bariatric surgery, within the context of individual, couple, and family relationships. The first author also has an extensive background in addictions and has taught courses within masters and doctoral programs, including work with medical students. Prior to conducting the study, the first author taught addictions related courses at multiple institutions and found that while students in mental health training programs obtain knowledge regarding substance abuse and chemical dependency, they are not always exposed to the topic of addictions more broadly define, as well as topics such as eating disorders and food addictions. Therefore, the author was interested in formally assessing knowledge, exposure, and experiences related to these topics in his class, through a series of assignments, (one of which included the survey used for this study). In evaluating positionality, the first author was transparent about his previous encounters when teaching students and the level of importance he places on creating opportunities to explore experiences and knowledge related to the topic areas. The author was also transparent about future projects that he might consider based on the results. For example, in the future, the author would like to eventually 
consider developing curriculum that could be tested, as one way to improve knowledge of eating disorders and related food addictions for clinicians. As noted, the first author explored potential biases based on his previous experiences in the classroom, his role as an academic administrator who often interfaces with clinical placement sites, his clinical experience, as well as what he has observed in the literature. This also included the first authors personal contextual factors, such as race, class, gender, and culture. The first author is the director of a research team, which usually includes a variety of students (undergraduate, graduate, and doctoral level) as well as colleagues who have a shared interests in various research areas. The first author has served as a former professor to the second and third authors of this study.

The second author is currently a Postdoctoral Research Fellow. He holds a doctoral degree in Marriage and Family Therapy, as well as obtained a Master of Health Science (MHS), with an emphasis in Mental Health and a certificate in health disparities, from the Bloomberg School of Public Health, Johns Hopkins University, after completing his doctorate. The second author has both qualitative and quantitative skills and often broaches research with a focus on mental health (broadly defined) and has an emphasis on topics that include gender, culture, sexuality, minority identities, health, public health, and mental health. The second author previously has served on the research team of the first author, and they have previously conducted several clinically focused studies, some of which have included such topics as obesity, body image, public health, mental health, food consumption, and identity. The second author is a Licensed Marriage and Family Therapist and an AAMFT Approved Supervisor, who utilizes Gestalt approaches with clients. The second author has worked with clients who present with a variety of mental health and relational/systemic issues. Likewise, the second author has worked with clients, taught courses, and mentored students in the United States and abroad, regarding topics related to eating disorders, among other important health, mental health, and public health topics. The second author is a former student of the first author but was not a student in the program where data was collected.

The second author explored potential biases based on his social location, being someone who was not born in the United States and someone who has worked both in the United States and in other countries. The author also explored any biases related to his previous education (both in the United States and Abroad), his experience working with clients in various clinical settings, and his personal culture, gender, and sex, and how this may inform his approach to research. The second author also was transparent about his personal theoretical orientation when working with clients and how this may inform how he conceptualizes treatment. This author was involved in the conceptualization of research questions, coding, writing, and editing of this research study.

The third author is an independently licensed marriage and family therapist who has previously worked at an inpatient, partial hospitalization program, and residential program for the treatment of eating disorders as a primary therapist. The third author explored potential biases based on his sex, exposure working with clients and client's family's recovering from eating disorders, and experience researching other food-related topics such as health disparities in weight loss. In evaluating where this author is in his life, he recognizes the importance he regards food addiction and other eating disorders having in mental health treatment and his perceived need for more education to future therapists on these specific issues. The third author was a former student to the program in which participants were interviewed; however, the study was performed several years post-graduation and no participants had any form of relationship to this author. This author was involved in the conceptualization of research questions, coding, writing, and editing of this research study. The authors also employed scientific rigor through the use of triangulation (Creswell \& Miller, 2000). Multiple coders (Golafshani, 2003) were used to analyze the data, which increases consistency and reliability of the findings. In addition, the authors coded the surveys independently before meeting together to develop the final 
themes. Triangulation was also utilized specifically related to the data. As mentioned, while this study focuses on the survey questions, the survey was a part of a larger assignment which included an experiential component as well as a self-narrative. In particular, the experiential component of the class was related to student's experiencing attending 12-step meetings related to eating disorders and food addictions (Moore et al., 2018). The self-narrative asked questions related to overall epistemology relate to food addictions and eating disorders. The authors were able to compare the results of the survey to the narratives that were turned in with the assignment. The narratives were not a part of the data set, but they were able to be referenced and may be used in the future for additional research. Further, both informal and formal mechanisms were incorporated regarding member checks (Bradshaw, 2001; Krefting, 1991). Given that the survey was structured as part of a course assignment, there were opportunities for informal discussions with students regarding their overall perspectives. After the survey portion of the assignment was submitted, students and the instructor were able to discuss their perspectives. Likewise, after data was further analyzed, the principal investigator was able to review some of the preliminary themes and was able to obtain feedback from students to assist with confirming the results of the study. In addition to informal opportunities, the first author was able to schedule individual meetings with students if there were any questions about data that emerged from the surveys.

The authors also considered transferability (Shenton, 2004) as it relates to the study. Transferability refers to the ability of the research findings to be applicable to others beyond the research study. It is referred to as the qualitative counterpart of generalizability, which is a concept that is used in quantitative research (Anney, 2014). Transferability, is a concept in qualitative research that suggests that finings in one context, may offer valuable lessons that could be used in other similar settings (Daniel, 2019). In particular, the research topic was developed based on a review of the literature in the field. Likewise, the overarching research questions as well as the survey questions were developed to assist in closing a gap in the literature. In addition, transferability was considered when thinking about the potential of research questions having implications for direct clinical practice (Malterud, 2001). Further, while the results are applicable to the MFT field, the authors have considered ways to apply results to other mental health professions and allied health professions. Further, the results will serve as a foundation for future inquiry that may include additional populations beyond master's level MFT students.

\section{Organization of Data}

To organize the data collected, researchers used the final list of themes derived from the coding process and applied the context of the overarching research questions by using participant data to support each theme. In developing this context, researchers used a representative quote directly from the data to introduce and demonstrate each theme. Further, researchers used supplemental quotes and paraphrases as well as collective data gathered from participants to further support each theme and to present research findings in a comprehensive and thorough report.

\section{Results}

Out of the research, four themes emerged as (1) defining food addiction, (2) perceptions of eating disorders, (3) conceptualizing systemic treatment, and (4) experiences in clinical training. Each theme is described in the context of answering the overarching research questions: "What is food addiction and how do you think about it as a Marriage and Family 
Therapist?" "How do you think about Binge Eating Disorder and Bulimia, within the context of Food addictions?" and "How do you conceptualize treatment?"

\section{Theme 1: Defining Food Addiction}

My understanding is that individuals who identify with being a food addict or have behaviors that are obsessive and compulsive that may be in denial of their behaviors, and have a tolerance, withdrawal, and cravings for food, are considered to be addicted to food. Individuals with food addiction are characterized by continuing these behaviors with or without the knowledge of the negative consequences that may result. While I do agree that there is a biological/physiological component with food addiction, I believe, as stated previously, that these behaviors are symptoms of something else. This could be a past/current trauma or a number of contributing factors that the individual began coping with in a negative way. (Brandy)

The first major theme developed out of the participants defining food addiction related to their unique understanding of food as an addiction through personal experiences and their training as an MFT. Out of the participants, all but four stated that they believed that food addiction should be a distinct diagnosis, with some in support having food addiction included in the next version of the DSM. For example, participant Eve who was in favor of the inclusion of food addiction in the next DSM stated, "Since food addiction cannot be determined by an individual's weight, it should be included within the DSM to identify dysfunctional behaviors that the person exhibits surrounding the intake of food." Two of the remaining four that did not support the addition of a diagnosis for food addiction reported that they were unsure and didn't know enough about it to draw a conclusion. Participant Brandy contributed her view to knowing that "I struggle with the concept of addiction being a disease. I understand that through further study and gaining more knowledge, on my part, I may have a different view in the future." Out of the two opposed, only one offered an explanation with the short explanation, "I think food addiction is an outward behavior of an inward problem" (Gus) while the other simply reported they believed the current diagnoses were sufficient.

In several participant descriptions, food addiction was associated to substance abuse and addiction, where some considered it a life-long battle, such as Jane, who elaborated: "I do not believe that this addiction can go away, but I do believe that the food addict can manage their addiction in different ways (psychoeducation, support from other addicts, family, friends, etc.)." Interestingly, one participant, Liz, even went so far to say that it, "maybe even harder to control [than other addictions] because we all can give up alcohol and live without it, but food is a necessity." Also supporting this notion, participant Casey stated, "I think that food addiction is often overlooked because food is not seen as a drug, and it is completely legal to overeat." Those in opposition of specifying food addiction as its own diagnosis viewed the topic in terms of a substance addiction as well, where Gus explained his understanding of food addiction as an "uncontrollable craving for excess food, where the consumption of food can mimic the chemical response similar to cocaine."

\section{Theme 2: Perceptions of Eating Disorders}

I think that they are distinct diagnoses that fall under the umbrella term of food addiction. These diagnoses are just forms of food addiction in that there are obsessive compulsive tendencies related to the interaction with food. (Joy) 
A second theme emerged surrounding the perception of eating disorders, specifically bulimia nervosa and binge eating disorder (BED) within the context of food addictions. Four participants considered both bulimia and BED as being under the category of food addiction, as Janice summarizes, "I believe that they are related to food addiction; in my opinion, food addiction is just the umbrella term and the eating disorders [are] within that umbrella." Five participants considered both to fall under food addiction and deserve their own diagnostic criteria. As Joy describes, "I think that they are distinct diagnoses that fall under the umbrella term of food addiction. These diagnoses are just forms of food addiction in that there are obsessive compulsive tendencies related to the interaction with food." Participant Casey indicated, "I think these criteria for all these disorders are different, as well as the treatments and causes so they should be recognized as distinct diagnoses," which represents the largest category of seven participants that believe all three should be separate diagnoses.

While there were statements made by participants specifying their view that either food addiction should be an umbrella term for both bulimia and BED to fall under, they should all contain their own diagnostic criteria, or a combination of both; a total of sixteen participants perceived that food addiction was somehow related to BED and bulimia and should be identified as such. Out of the remaining two participant contributions, one participant believed that food addiction should fall under the same category as other addictions, and one participant believed that food addiction along with BED and bulimia should not be in the DSM at all.

\section{Theme 3: Conceptualizing Systemic Treatment}

Food addiction just like other addictions often may stem from a trauma experience or a genetic disposition. Relationships may often be impacted by the addiction, functioning around the addiction itself... Working with a food addict may be very challenging at times. From my understanding, they may have the same symptoms as someone with a drug/alcohol addiction. It is important to get a complete history around the addiction. (Mark)

The third theme was shaped because of asking the participants how they would conceptualize treatment with a client that had food addiction. Their answers not only encompassed what theoretical model they would utilize, but also their ideas on who would be included in treatment and how to treat the addiction. Participants were allowed to suggest any and however many theoretical models they would find helpful in the treatment of food addiction. Out of the sixteen participants, fourteen suggested they would use cognitive behavioral therapy (CBT) as either a primary or secondary model to inform their treatment of someone struggling with food addiction. Many participants explained their utilization of CBT as best represented by Tina's statement:

CBT, I believe is the most effective evidence-based treatment for eating disorders, therefore, it should be beneficial for food addictions. I would first work with clients on their behavior by creating a food plan and educating them on different coping strategies to manage their feeling of depression and other emotions that may surface. Next cognitive restructuring would take place to help the client recognize their irrational belief and patterns. The person's selfesteem confidence, body image, and relationship problem if any would be addressed. Triggers would be identified, as well as a plan implemented to reduce them. As always, a relapse prevention plan would be devised. 
However, there were several other models that were mentioned whether as a primary or secondary model. For example, three participants reported they would apply treatment using narrative therapy, "in order for the client to explain their journey with me and how they became a food addict in the first place," as put by participant Sandy. Two participants reported including emotionally focused therapy (EFT) to inform their work. For example, participant Sue described, "Underneath the food addiction may be emotional needs and attachment issues that have not been met by people and have been substituted with food." Similarly, acceptance and commitment therapy (ACT) was mentioned by two participants, as well as two mentions of structural therapy and motivational interviewing, one solution focused, and one intergenerational family therapy.

Notably, every participant referenced the involvement of family and significant other's as being important in their conceptualization of treatment. Participant Brandy addressed this matter by stating: "Considering that I currently believe that addiction is a symptom of another issue and/or a way to cope with the problem, whatever that may be, I believe that partners and families play an integral role in the healing of the individual with food addiction." Additionally, some participants recognized that in relation to the client, "family members may worry about them, change their own diet/lifestyle to accommodate their family and family member battling the food addiction, or may even be one of the contributing factors to the food addict's problem," as participant Jane explained. A few participants also included in their conceptualizations the utilization of group therapy and other groups such as Over-Eater's Anonymous. Similarly, several participants suggested they would incorporate psychoeducation, relapse prevention planning, as well as addressing co-occurring disorders and focusing on strengthening the client's social support system when treating food addiction.

\section{Theme 4: Experiences in Clinical Training}

I have not worked with a food addict but one who presents with alcohol, drug and sex addictions... In therapy, I focused on identifying relapse triggers and we worked on a plan to avoid the triggers... I found that the interventions used for one addiction, worked for the others. (Patricia)

The fourth theme developed from asking participants questions about their experiences working with food addiction both prior to and during clinical training. To better grasp students' perspectives regarding the research topic, the authors sought further insight to previous and current experiences that students had regarding food addiction.

Prior to beginning training as an MFT only two participants described having exposure working with someone that had a food addiction: one being through work and the other through personal experiences. While receiving clinical training, only four participants reported working with clients who had food addiction or a similar phenomenon. One participant, Tina, described working with a client that had co-occurring addictions where, "once she [the client] had stopped using drugs, she noticed that she started to eat more. She told me that she just could not help herself and did not understand why it was so hard to stop eating." Participant Eve reported that while she had not encountered any clients experiencing food addiction that she had, "encountered several clients that must manage their diets due to chronic health issues or diabetes." Yet most participants reported not having any experience working with clients that had a food addiction or similar phenomenon. 


\section{Discussion}

The findings within the research are like some of the existing research in that there has been some discussion regarding eating disorders among MFT students. However, the results suggest that the findings are novel in that there has been less discussion specifically related to the notion of food addictions and its connection to or distinction from Binge Eating Disorder and/or other eating disorders found in the Diagnostic and Statistical Manual. In addition, while it is clear that MFT students in the study were versed in how they conceptualized systemic treatment, their knowledge base appeared to be more so from a general understanding of MFT theory, with less education specifically about how to work with clients who may present with issues related to "food addictions" as well as eating disorders that are currently diagnosed in clinical treatment. When asking about exposure to working with clients who may deal with food addiction, food compulsion, or Binge Eating Disorder, it was communicated that most students receive no real exposure to the treatment topics or populations in a real meaningful way. This may impact one's ability to work with clients if additional didactic or clinical training is not provided skillfully and appropriately.

\section{Recommendations}

The authors believe that it may be warranted to explore what MFT's know about food addiction and related concerns. It may be worth it for master's level training programs to do an inventory of their curriculum to explore if they adequately incorporate training in eating disorders. MFT training programs may also explore potential ways to introduce the topics of eating disorders and addiction into their curriculum in both didactic courses as well as more clinically active courses. Further, training programs may consider opportunities to develop relationships with local agencies that may be able to assist in providing internships for students to gain practical skills in working with clients who may present with issues related to food addiction or who may have food related concerns. In addition to training directly obtained in the master's program, MFT educators may consider collaboration with organizations that may offer post-graduate training in eating disorders and addictions. Likewise, MFT educators may consider ways to develop their own specific training that highlights the systems approach to working with clients who present with food addiction or weight related concerns. Further, other mental health professions and medical professions may consider ways to promote interdisciplinary collaboration and training regarding this topic.

\section{Limitations of the Research}

There are limitations in every study. The major limitations of the current study include a convenience sample in that the students that participated in the study were from one class in an MFT training program. However, the authors were still able to obtain data that can be leveraged in a future study with a larger data set. Likewise, the data was rich in providing information about how some students are training in an MFT training program, which can be duplicated nationally in a follow-up study. With the demographics, most of the students identified as female, which means that there was less opportunity to understand how male students perceive the topic. However, the sex make-up is not surprising, given that there are generally more female students than male students in MFT training programs at the master's level. When considering training level, one limitation could be the students that participated were from a master's level training program and not a doctoral program in MFT. However, given that the master's degree in MFT is the terminal degree and given that most doctoral programs train students in advanced research, there is an argument to be made as to why the 
research should be done at the master's level. Though perhaps, exploring the topic with doctoral students in clinically oriented MFT doctoral programs (Ph.D., DMFT, or Psy.D.) may be warranted. One limitation is that the research consisted of a qualitative survey. It may be warranted to consider utilizing a quantitative approach especially if one wants to objectively assess knowledge of food addiction and/or test an intervention. Qualitative research is not generalizable, therefore the results in the study must be viewed in context and cannot be generalized to the larger population. However, the data provides some insight which could be further tested in a quantitative study.

\section{Future Directions in Research}

Based on the results of the research, the authors see a need to continue to explore the topic of food addiction specifically regarding knowledge (MFT training in didactic, clinical, and experiential domains) as well as competency in working with clients who may present with issues related to food addiction. Therefore, a larger study is being planned to better understand the practices of MFT programs as it relates to addiction training (generally) and topics specifically related to food addiction (including obesity, Bulimia, Binge Eating Disorder, weight preoccupation, among others). This research may expand to training programs in other helping professions (counseling, psychology, and social work). Likewise, research may include training programs in medicine and allied health professions (medical school, nursing, pharmacy, registered dietician, and nutrition). Further research may include the development and testing of various interventions to increase knowledge and clinical skill set.

\section{References}

American Psychiatric Association. (1994). Diagnostic and statistical manual of mental disorders ( $4^{\text {th }}$ ed.). American Psychiatric Association.

American Psychiatric Association. (2013). Diagnostic and statistical manual of mental disorders $\left(5^{\text {th }}\right.$ ed.). American Psychiatric Publishing.

Anney, V. N. (2014). Ensuring the quality of the findings of qualitative research: Looking at trustworthiness criteria. Journal of Emerging Trends in Educational Research and Policy Studies, 5(2), 272-281.

Avena, N. M., Bocarsly, M. E., Rada, P., Kim, A., \& Hoebel, B. G. (2008). After daily bingeing on a sucrose solution, food deprivation induces anxiety and accumbens dopamine/acetylcholine imbalance. Physiology \& Behavior, 94(3), 309-315.

Avena, N. M., Rada, P., \& Hoebel, B. G. (2008). Evidence for sugar addiction: Behavioral and neurochemical effects of intermittent, excessive sugar intake. Neuroscience \& Biobehavioral Reviews, 32(1), 20-39.

Ayres, L., Kavanaugh, K., \& Knafl, K. A. (2003). Within-case and across-case approaches to qualitative data analysis. Qualitative Health Research, 13(6), 871-883.

Basit, T. (2003). Manual or electronic? The role of coding in qualitative data analysis. Educational research, 45(2), 143-154.

Berger, R. (2015). Now I see it, now I don't: Researcher's position and reflexivity in qualitative research. Qualitative Research, 15(2), 219-234.

Bowen, M. (1978). Family therapy in clinical practice. J. Aronson.

Bradshaw, M. (2001). Contracts and member checks in qualitative research in human geography: Reason for caution? Area, 33(2), 202-211.

Burnard, P. (1991). A method of analysing interview transcripts in qualitative research. Nurse Education Today, 11(6), 461-466.

Corbin, J. M., \& Strauss, A. (1990). Grounded theory research: Procedures, canons, and 
evaluative criteria. Qualitative Sociology, 13(1), 3-21.

Creswell, J. W., \& Miller, D. L. (2000). Determining validity in qualitative inquiry. Theory into Practice, 39(3), 124-130.

Daniel, B. K. (2019, June). What constitutes a good qualitative research study? Fundamental dimensions and indicators of rigour in qualitative research: The TACT framework. Proceedings of the European Conference of Research Methods for Business \& Management Studies.

Davis, C., \& Carter, J. C. (2009). Compulsive overeating as an addiction disorder. A review of theory and evidence. Appetite, 53(1), 1-8.

Davis, C., Curtis, C., Levitan, R. D., Carter, J. C., Kaplan, A. S., \& Kennedy, J. L. (2011). Evidence that 'food addiction' is a valid phenotype of obesity. Appetite, 57(3), 711717.

De Silva, P., \& Eysenck, S. (1987). Personality and addictiveness in anorexic and bulimic patients. Personality and Individual Differences, 8(5), 749-751.

Earle, V. (2010). Phenomenology as research method or substantive metaphysics? An overview of phenomenology's uses in nursing. Nursing Philosophy, 11(4), 286-296.

Eisler, I., Dare, C., Russell, G. F., Szmukler, G., le Grange, D., \& Dodge, E. (1997). Family and individual therapy in anorexia nervosa: A 5-year follow-up. Archives of General Psychiatry, 54(11), 1025-1030.

Elo, S., \& Kyngäs, H. (2008). The qualitative content analysis process. Journal of Advanced Nursing, 62(1), 107-115.

Fairburn, C. G. (2005). Evidence-based treatment of anorexia nervosa. International Journal of Eating Disorders, 37(Suppl.), S26-S30. Doi:10.1002/eat.20112

Fairburn, C. G., Cooper, Z., Doll, H. A., Norman, P., \& O'Connor, M. (2000). The natural course of bulimia nervosa and binge eating disorder in young women. Archives of General psychiatry, 57(7), 659-665.

Fairburn, C. G., Doll, H. A., Welch, S. L., Hay, P. J., Davies, B. A., \& O’Connor, M. E. (1998). Risk factors for binge eating disorder: A community-based, case-control study. Archives of General Psychiatry, 55(5), 425-432.

Flyvbjerg, B. (2006). Five misunderstandings about case-study research. Qualitative Inquiry, 12(2), 219-245.

Gearhardt, A. N., Corbin, W. R., \& Brownell, K. D. (2009). Preliminary validation of the Yale food addiction scale. Appetite, 52(2), 430-436.

Gearhardt, A., Davis, C., Kuschner, R., \& Brownell, K. (2011). The addiction potential of hyperpalatable foods. Current Drug Abuse Reviews, 4(3), 140-145.

Gearhardt, A., White, M., \& Potenza, M. (2011). Binge eating disorder and food addiction. Current Drug Abuse Reviews, 4(3), 201-207.

Geist, R., Heinmaa, M., Stephens, D., Davis, R., \& Katzman, D. K. (2000). Comparison of family therapy and family group psychoeducation in adolescents with anorexia nervosa. The Canadian Journal of Psychiatry, 45(2), 173-178.

Gerstein, F., \& Pollack, F. (2016). Two case studies on family work with eating disorders and body image issues. Clinical Social Work Journal, 44(1), 69-77.

Gilgun, J. (2010). Reflexivity and qualitative research. Current Issues in Qualitative Research, 1(2), 1-8.

Gläser, J., \& Laudel, G. (2013, March). Life with and without coding: Two methods for earlystage data analysis in qualitative research aiming at causal explanations. In Forum Qualitative Sozialforschung/Forum: Qualitative Social Research, 14(2). https://doi.org/10.17169/fqs-14.2.1886

Golafshani, N. (2003). Understanding reliability and validity in qualitative research. The Qualitative Report, 8(4), 597-606. https://doi.org/10.46743/2160-3715/2003.1870 
Goldstein, R. Z., \& Volkow, N. D. (2011). Dysfunction of the prefrontal cortex in addiction: neuroimaging findings and clinical implications. Nature Reviews Neuroscience, 12(11), 652-669.

Hebebrand, J., Albayrak, Ö., Adan, R., Antel, J., Dieguez, C., de Jong, J., Leng, G., Menzies, J., Mercer, J. G., Murphy, M., van der Plasse, G., \& Dickson, S. L. (2014). "Eating addiction," rather than "food addiction," better captures addictive-like eating behavior. Neuroscience \& Biobehavioral Reviews, 47, 295-306.

Hetherington, M. M., \& MacDiarmid, J. I. (1993). "Chocolate addiction": A preliminary study of its description and its relationship to problem eating. Appetite, 21(3), 233-246.

Hone-Blanchet, A., \& Fecteau, S. (2014). Overlap of food addiction and substance use disorders definitions: Analysis of animal and human studies. Neuropharmacology, 85, 81-90.

Imperatori, C., Innamorati, M., Contardi, A., Continisio, M., Tamburello, S., Lamis, D. A., Tamburello, A., \& Fabbricatore, M. (2014). The association among food addiction, binge eating severity and psychopathology in obese and overweight patients attending low-energy-diet therapy. Comprehensive Psychiatry, 55(6), 1358-1362.

Kirby, J. S., Fischer, M. S., Raney, T. J., Baucom, D. H., \& Bulik, C. M. (2016). Couple-based interventions in the treatment of adult anorexia nervosa: A brief case example of UCAN. Psychotherapy, 53(2), 241.

Kitzinger, J. (1995). Qualitative research: Introducing focus groups. British Medical Journal, 311(7000), 299-302.

Krefting, L. (1991). Rigor in qualitative research: The assessment of trustworthiness. American Journal of Occupational Therapy, 45(3), 214-222.

Lafrance Robinson, A., Dolhanty, J., Stillar, A., Henderson, K., \& Mayman, S. (2016). Emotion-focused family therapy for eating disorders across the lifespan: A pilot study of a 2-day transdiagnostic intervention for parents. Clinical Psychology \& Psychotherapy, 23(1), 14-23.

Lambert, V. A., \& Lambert, C. E. Qualitative descriptive research: An acceptable design. Pacific Rim International Journal of Nursing Research, 16(4), 255-256.

Lemmon, C. R., \& Josephson, A. M. (2001). Family therapy for eating disorders. Child and Adolescent Psychiatric Clinics of North America, 10(3), 519-542.

Lock, J., \& le Grange, D. (2005). Family-based treatment of eating disorders. International Journal of Eating Disorders, 37(S1), S64-S67.

Malterud, K. (2001). Qualitative research: Standards, challenges, and guidelines. The Lancet, 358(9280), 483-488.

McCracken, G. (1988) The long interview (Vol. 13). Sage Publications Inc.. http://dx.doi.org/10.4135/9781412986229

Merriam, S. B. (2002). Introduction to qualitative research. Qualitative Research in Practice: Examples for Discussion and Analysis, 1, 1-17.

Meule, A., \& Gearhardt, A. (2014). Food addiction in the light of DSM-5. Nutrients, 6(9), 3653-3671.

Minuchin, S., \& Fishman, H. C. (2009). Family therapy techniques. Harvard University Press.

Moore, D. D., \& Cooper, C. E. (2016). Life after bariatric surgery: Perceptions of male patients and their intimate relationships. Journal of Marital and Family Therapy, 42(3), 495508.

Moore, D., Lin, C., Kamboj, S., Pasicel, L., \& Tam, R. (2018). MFT students' recount experiences of attending phone and online Overeaters Anonymous Meetings. Contemporary Family Therapy, 40, 357-371. https://doi.org/10.1007/s10591-0189456-Z

Neergaard, M. A., Olesen, F., Andersen, R. S., \& Sondergaard, J. (2009). Qualitative 
description-the poor cousin of health research? BMC Medical Research Methodology, 9(1), 52-56. Doi:10.1186/1471-2288-9-52

Nichols, M. P., \& Schwartz, R. C. (2005). The essentials of family therapy. Pearson/Allyn and Bacon.

Nutt, D. J., King, L. A., \& Phillips, L. D. (2010). Drug harms in the UK: A multicriteria decision analysis. The Lancet, 376(9752), 1558-1565.

Palaganas, E. C., Sanchez, M. C., Molintas, M., Visitacion, P., \& Caricativo, R. D. (2017). Reflexivity in qualitative research: A Journey of Learning. The Qualitative Report, 22(2), 426-438. https://doi.org/10.46743/2160-3715/2017.2552

Pelchat, M. L. (2009). Food addiction in humans. The Journal of Nutrition, 139(3), 620-622.

Pelchat, M. L., Johnson, A., Chan, R., Valdez, J., \& Ragland, J. D. (2004). Images of desire: Food-craving activation during fMRI. Neuroimage, 23(4), 1486-1493.

Pressman, P., Clemens, R. A., \& Rodriguez, H. A. (2015). Food addiction: Clinical reality or mythology. The American Journal of Medicine, 128(11), 1165-1166.

Pursey, K. M., Gearhardt, A. N., \& Burrows, T. L. (2016). The relationship between "food addiction" and visceral adiposity in young females. Physiology \& Behavior, 157, 9-12.

Randolph, T. G. (1956). The descriptive features of food addiction. Addictive eating and drinking. Quarterly Journal of Studies on Alcohol, 17(2), 198-224.

Rogers, P. J., \& Smit, H. J. (2000). Food craving and food "addiction": A critical review of the evidence from a biopsychosocial perspective. Pharmacology Biochemistry and Behavior, 66(1), 3-14.

Rogers, P. J. (2017). Food and drug addictions: Similarities and differences. Pharmacology Biochemistry and Behavior, 153, 182-190.

Sandelowski, M. (2000). Focus on research methods: Whatever happened to qualitative description? Research in Nursing \& Health, 23(4), 334-340.

Schienle, A., Schäfer, A., Hermann, A., \& Vaitl, D. (2009). Binge-eating disorder: Reward sensitivity and brain activation to images of food. Biological Psychiatry, 65(8), 654661.

Schulte, E. M., Joyner, M. A., Potenza, M. N., Grilo, C. M., \& Gearhardt, A. N. (2015). Current considerations regarding food addiction. Current Psychiatry Reports, 17(4), 19.

Schulte, E. M., Tuttle, H. M., \& Gearhardt, A. N. (2016). Belief in food addiction and obesityrelated policy support. PloS one, 11(1), e0147557.

Shenton, A. K. (2004). Strategies for ensuring trustworthiness in qualitative research projects. Education for Information, 22(2), 63-75.

Siegel, M., Brisman, J., \& Weinshel, M. (2009). Surviving an eating disorder: Strategies for families and friends. Collins Living.

Starks, H., \& Trinidad, S. B. (2007). Choose your method: A comparison of phenomenology, discourse analysis, and grounded theory. Qualitative Health Research, 17(10), 13721380.

Szmukler, G. I., \& Tantam, D. (1984). Anorexia nervosa: Starvation dependence. British Journal of Medical Psychology, 57(4), 303-310.

Tesch, R. (1990). Qualitative research: Analysis types and software tools. Psychology Press.

Treasure, J., Smith, G., \& Crane, A. (2007). Skills-based learning for caring for a loved one with an eating disorder: The new Maudsley method. Routledge.

Volkow, N. D., Wang, G. J., Fowler, J. S., Tomasi, D., \& Baler, R. (2012). Food and drug reward: overlapping circuits in human obesity and addiction. Current Topics in Behavioral Neurosciences, 11, 1-24. https://doi.org/10.1007/7854_2011_169

Ziauddeen, H., \& Fletcher, P. C. (2013). Is food addiction a valid and useful concept? Obesity Reviews, 14(1), 19-28. 


\section{Appendix A}

1. How do you define "Food Addiction?"

2. What are your thoughts about the notion of "food addiction?

3. How do you conceptualize "food addiction" within the context of couple and family relationships?

4. While there has been a significant amount of research regarding "food addictions" it is still a highly debated topic. Do you support or not support the inclusion of food addiction into the next version of the DSM?

5. How do you view binge eating disorder (BED) and Bulimia? Do you view them as related to the notion of "food addiction" or do you see them as distinct diagnoses? Please elaborate:

6. From a systemic or MFT perspective, how do you think about working with someone who identifies as a "food addict?"

7. What theoretical model would you utilize when working with a client who "struggles" with food addiction?

8. In your clinical training (at the Family Therapy Center or at your placement site) have you worked with clients who experienced food addiction or a similar phenomenon? (If so, provide a brief synopsis).

9. In your previous work experience prior to starting the graduate program in MFT, have you worked with clients who experienced food addiction? 
Appendix B

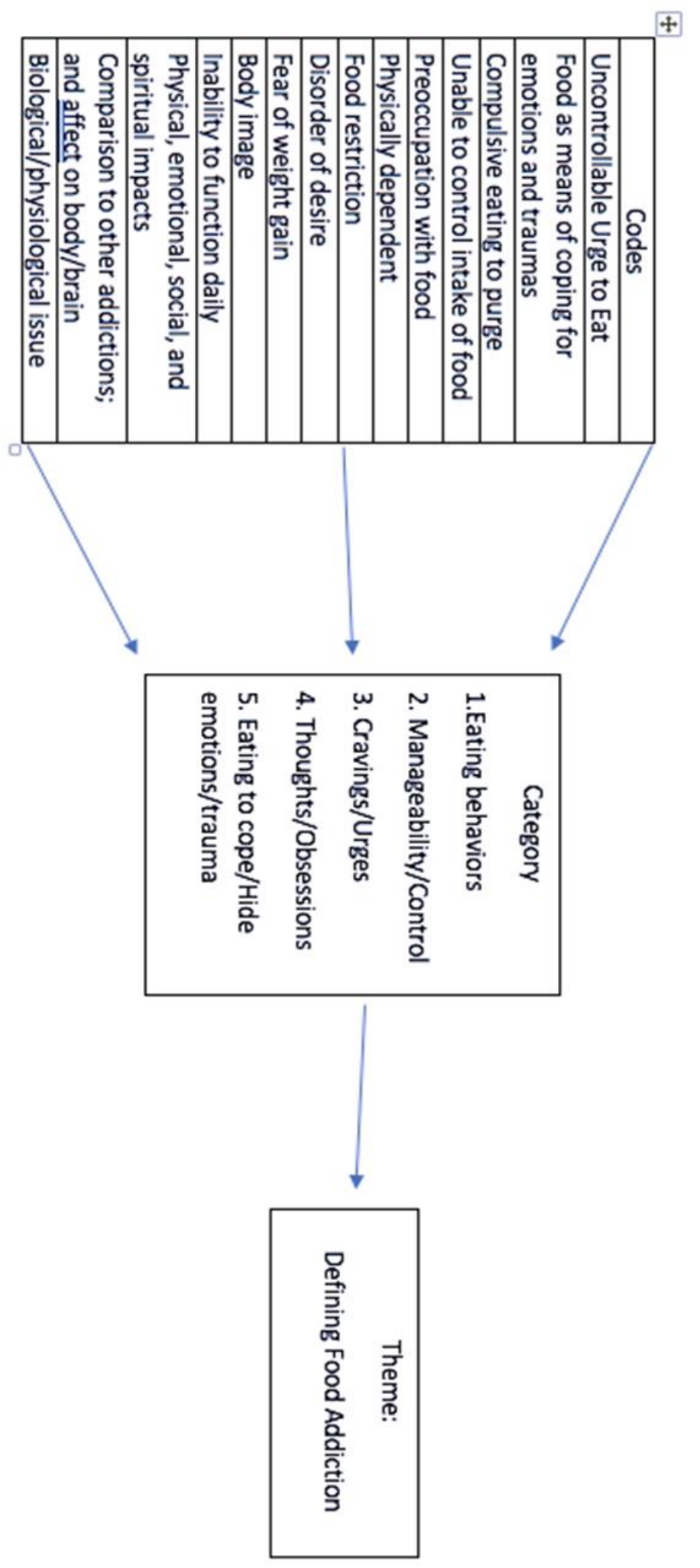

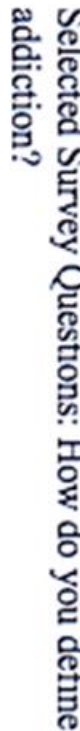

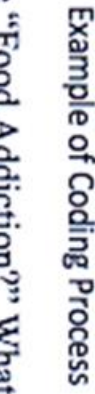

हี

言

㝘

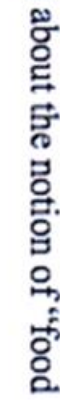




\section{Author Note}

Darren D. Moore, PhD., LMFT, AAMFT Approved Supervisor, is an Associate Professor and Program Director in the Master's program in Marriage and Family Therapy at Touro University Worldwide. His research is focused on obesity, weight loss, eating disorders, addictions, health disparities, men, couple and family relationships, fatherhood/fatherlessness, as well as diversity, equity, and inclusion, within the workplace and in higher education. He holds a doctorate in Human Development, with a concentration in Marriage and Family Therapy from Virginia Tech and he later obtained a Masters in Higher and Postsecondary Education from Teachers College, Columbia University. Please direct correspondence to Mooredd2012@gmail.com.

Chichun Lin earned a Doctorate of Psychology (Psy.D.) in Marital and Family Therapy (Alliant International University) and three Master's degrees in Counseling Psychology (East China Normal University), Marital and Family Therapy (Alliant International University), and Mental Health (Johns Hopkins University). Dr. Lin is an American Association for Marriage and Family Therapy approved supervisor and a registered clinical counselor approved by British Columbia Association of Clinical Counsellors. He currently serves as a Postdoctoral Research Fellow at Stigma and Resilience Among Vulnerable Youth Centre, University of British Columbia, Vancouver, Canada. Please direct correspondence to Chichun.lin@ubc.ca.

Clinton E. Cooper, LMFT, is the owner/operator of a private therapy, coaching, and consulting practice in Scottsdale, AZ, and is licensed in Arizona and Georgia. He serves as a research associate and a senior member of Dr. Moore's research team. Clinton's research interests include: exercise, weight, and eating-related disorders; couples issues, health disparities in minority populations, sexuality, gender identity, and elder populations within individual, couple, family, and larger systemic relationships. Clinton obtained his undergraduate degree in Psychology from High Point University and his graduate degree in Marriage and Family Therapy from Mercer University School of Medicine. Please direct correspondence to $\underline{\text { Clint @ clintcoopertherapy.com. }}$

Copyright 2021: Darren D. Moore, Chichun Lin, Clinton E. Cooper, and Nova Southeastern University.

\section{Article Citation}

Moore, D. D., Lin, C., \& Cooper, C. E. (2021). A need of further training for marriage and family therapy students on food addiction and related eating disorders. The Qualitative Report, 26(10), 3046-3066. https://doi.org/10.46743/2160-3715/2021.4533 